\title{
The role of knowledge management in innovation
}

\section{The Authors}

Marina du Plessis, Lyttelton, South Africa.

\begin{abstract}
Purpose - This article seeks to clarify the role of knowledge management in innovation as an aid to addressing this complexity. The article seeks to identify the drivers for application of knowledge management in innovation. It also details the nature of the role of knowledge management in innovation as well as its value proposition.
\end{abstract}

Design/methodology/approach - The methodology used was literature research and some personal experiences and interpretations.

Findings - In the fast changing business world of today, innovation has become the mainstay of organizations. The nature of global economic growth has been changed by the speed of innovation, which has been made possible by rapidly evolving technology, shorter product lifecycles and a higher rate of new product development. The complexity of innovation has been increased by growth in the amount of knowledge available to organizations.

Originality/value - Innovation is extremely dependent on the availability of knowledge and therefore the complexity created by the explosion of richness and reach of knowledge has to be recognized and managed to ensure successful innovation.

\section{Introduction}

In the fast changing business world of today, innovation has become the mainstay of every organization. The nature of global economic growth has been changed by the speed of innovation, which has been made possible by rapidly evolving technology, shorter product lifecycles and a higher rate of new product development. Organizations have to ensure that their business strategies are innovative to build and sustain competitive advantage. Innovation has, however, become increasingly complex due to changing customer needs, extensive competitive pressure and rapid technological change (Cavusgil et al., 2003). The complexity of innovation has also been increased by growth in the amount of knowledge available to organizations as basis for innovation. Innovation is extremely dependent on the availability of knowledge and therefore the complexity created by the explosion of richness and reach of knowledge has to be identified and managed to ensure successful innovation (Adams and Lamont, 
2003; Cardinal et al., 2001; Darroch and McNaughton, 2002; Pyka, 2002; Shani et al., 2003).

Due to the fact that very little clarity exists in current literature, this article aims to clarify the role of knowledge management in innovation. In order to facilitate this, the definition and nature of both knowledge management and innovation will be investigated. The article also aims to identify the drivers for the application of knowledge management in innovation as well as the value proposition of the utilization of knowledge management in the innovation process.

\section{Definitions}

Innovation is defined in many different ways in the literature. According to Chen et al. (2004) innovation refers to the introduction of a new combination of the essential factors of production into the production system. Innovation capital is the competence of organizing and implementing research and development, bringing forth the new technology and the new product to meet the demands of customers. It involves the new product, the new technology, the new market, the new material and the new combination. Cardinal et al. (2001) indicate that the innovation process encompasses the technical, physical, and knowledge-based activities that are central in forming product development routines.

Herkema (2003) defines innovation as a knowledge process aimed at creating new knowledge geared towards the development of commercial and viable solutions. Innovation is a process wherein knowledge is acquired, shared and assimilated with the aim to create new knowledge, which embodies products and services. Herkema (2003) also states that innovation is the adoption of an idea or behavior that is new to the organization. The innovation can be a new product, a new service or a new technology. Innovation is related to change, which can be radical or incremental.

Innovation can broadly be described as the implementation of discoveries and interventions and the process by which new outcomes, whether products, systems or processes, come into being (Gloet and Terziovski, 2004). The authors distinguish radical and incremental innovation from one another. Incremental innovations present themselves as line extensions or modifications of existing products. They are usually classified as market-pull innovations. Incremental innovation does not require significant departure from existing business practices and are therefore likely to enhance existing internal competencies by providing the opportunity to build on existing know-how. Radical innovations are likely to be competence-destroying, often making existing skills and knowledge redundant and necessitating different management practices. Radical innovations often put the business at risk because they are more difficult to commercialize. Radical innovations are considered crucial to long-term success as they involve development and application of new technology, some of which may change existing market structures. Companies that facilitate both 
radical and incremental innovation are more successful than organizations that focus on one or the other.

The author defines innovation as the creation of new knowledge and ideas to facilitate new business outcomes, aimed at improving internal business processes and structures and to create market driven products and services. Innovation encompasses both radical and incremental innovation.

Many knowledge management definitions exist. For the purpose of this paper, only selected definitions will be focused on. Gloet and Terziovski (2004) describe knowledge management as the formalization of and access to experience, knowledge, and expertise that create new capabilities, enable superior performance, encourage innovation, and enhance customer value. The authors also describe knowledge management as an umbrella term for a variety of interlocking terms, such as knowledge creation, knowledge valuation and metrics, knowledge mapping and indexing, knowledge transport, storage and distribution and knowledge sharing.

Darroch and McNaughton (2002) indicate that knowledge management is a management function that creates or locates knowledge, manages the flow of knowledge and ensures that knowledge is used effectively and efficiently for the long-term benefit of the organization. In the authors' opinion an organization that demonstrates competence in knowledge management has a knowledgeorientation and that knowledge management therefore becomes a guiding business philosophy that influences strategies undertaken by an organization's managers.

Parlby and Taylor (2000) is of the opinion that knowledge management is about supporting innovation, the generation of new ideas and the exploitation of the organization's thinking power. Knowledge management also includes capturing insight and experience to make them available and useable when, where and by whom it is required. Knowledge management allows easy access to expertise and know-how, whether it is formally recorded or in someone's mind. Knowledge management further allows collaboration, knowledge sharing, continual learning and improvement. It underpins better quality decision-making and ensures that the value and contribution of intellectual assets, as well as their effectiveness and their exploitation, is well understood.

In the author's opinion, knowledge management is as a planned, structured approach to manage the creation, sharing, harvesting and leveraging of knowledge as an organizational asset, to enhance a company's ability, speed and effectiveness in delivering products or services for the benefit of clients, in line with its business strategy. Knowledge management takes place on three levels, namely the individual level, team level and organizational level. It is a holistic solution incorporating a variety of perspectives, namely people, process, culture and technology perspectives, all of which carry equal weighting in 
managing knowledge (Du Plessis and Boon, 2004). Knowledge management is not solely focused on innovation, but it creates an environment conducive for innovation to take place.

\section{Drivers of the application of knowledge management in innovation}

According to the literature there are three main drivers of the application of knowledge management in innovation.

The first basic driver for knowledge management's role in innovation in today's business environment is to create, build and maintain competitive advantage through utilization of knowledge and through collaboration practices. Cavusgil et al. (2003) indicate that building and sustaining an innovation program has, however, become increasingly complex due to changing customer needs, extensive competitive pressure and rapid technological change. Organizations find it increasingly difficult to internalize innovations. Some large organizations such as Xerox and Hitachi have therefore started working collaboratively across organizational boundaries to ensure sustained innovation and competitive advantage (Cavusgil et al., 2003). Knowledge management can facilitate such collaboration. Close collaborative relationships can provide access to the processes other organizations use that could be applied in different contexts. Acquiring knowledge and skills through collaboration is considered to be an effective and efficient way of successful innovation.

The second driver of the role of knowledge management in innovation is that knowledge is a resource used to reduce complexity in the innovation process, and managing knowledge as resource will consequently be of significant importance. Innovation is extremely dependent on the availability of knowledge and therefore the complexity created by the explosion of richness and reach of knowledge has to be recognized and managed (Adams and Lamont, 2003; Cardinal et al., 2001; Darroch and McNaughton, 2002; Pyka, 2002; Shani et al., 2003). According to Shani et al. (2003) the upsurge in the amount of knowledge that is readily available to organizations seems to add increased complexity to the design and management of new product development, but this complexity can be addressed by knowledge management and knowledge-intensive units in the organization that are strategic in nature.

Cavusgil et al. (2003) agree that knowledge management is a mechanism through which innovation complexity can be addressed. It assists in managing new knowledge created through the innovation process, but also in managing existing knowledge as a resource used as input to the innovation process. Cavusgil et al. (2003) are of the opinion that firms that create and use knowledge rapidly and effectively are able to innovate faster and more successfully than those that do not. According to Pyka (2002), creation of innovation networks are driven by synergistic creation and management of knowledge. 
The third driver of applying knowledge management to the benefit of the innovation process is the integration of knowledge both internal and external to the organization, thus making it more available and accessible. Knowledge integration implies that timely insights can be made available to be drawn at the appropriate juncture for sense making, i.e. knowledge can be exchanged, shared, evolved, refined and made available at the point of need. Knowledge integration via knowledge management platforms, tools and processes must therefore facilitate reflection and dialogue to allow personal and organizational learning and innovation. This requires linkability, adaptability and dynamic representation of business information and knowledge. Without effective information and knowledge management that drives knowledge integration, which in turn underpins innovation, organizations could be underutilizing knowledge as an innovation resource (Baddi and Sharif, 2003; Chen et al., 2004).

In conclusion, it can be said that knowledge management systems have a distinctive contribution in the development of sustainable competitive advantage through innovation. Whilst information and knowledge management systems alone do not possess the qualities required to provide organizations with sustainable competitive advantage, the bundling of knowledge management systems with other firm resources and core competencies is the key to developing and maintaining sustainable competitive advantage through product and process innovation. In such a position, knowledge management systems play a major role in the conversion of learning capabilities and core competencies into sustainable advantage by enabling and revitalizing organizational learning and resource development processes (Adams and Lamont, 2003):

Knowledge management and innovation configuration determine how the firm can capitalize and create new knowledge, providing context wherin new product development efforts are designed, developed and completed (Shani et al., 2003).

\section{The nature of the role of knowledge management in innovation}

Knowledge and knowledge management fulfils a myriad functions in the innovation realm.

The first major role that knowledge management plays in innovation is enabling the sharing and codification of tacit knowledge. Tacit knowledge sharing is critical for organizations' innovation capability (Cavusgil et al., 2003). According to the authors, firms with high innovation potential employ a learning-by-doing effect that makes it difficult for competitors to buy this know-how in the market and also makes it difficult to replicate. According to Cardinal et al. (2001), replication of knowledge-based competitive advantage is inhibited by two factors. Causal 
ambiguity leads to specific practices or inputs (e.g. knowledge) for replication being unknown. Secondly, social complexity or unique firm history that produces the knowledge makes it difficult to replicate. Getting tacit knowledge from customers and suppliers is a valuable source for organizations' innovation programs due to scarcity of such knowledge that can be used as input for innovation. The authors also indicate that collaboration between organizations plays a significant role in sharing of tacit knowledge, which in turn positively impacts innovation capability (Cavusgil et al., 2003). The role of collaboration will be discussed in more detail later in this section.

The sharing of tacit knowledge as resource for innovation is especially important in developing fields where not a lot of explicit knowledge exists, such as biotechnology. Innovators in these fields combine partially codified knowledge with complimentary resources such as cross-functional teams or learning-bydoing capabilities, which leads to new product and process innovations (Cardinal et al., 2001).

Cardinal et al. (2001) indicate that, in situations where a lot of tacit knowledge is used for innovation, collaboration between cross-functional teams is essential. Such interactions produce the routines that create new "recipes". However, the knowledge in these "recipes" is not necessarily codified, but often stays within the innovation and operational teams' routines and skills. Knowledge management can assist in the accessibility of such tacit knowledge and the codification thereof.

The author is of the opinion that the fact that knowledge is not available in explicit format makes knowledge sharing and the application of knowledge in the innovation process difficult. Organizations are firstly not aware of the stocks of tacit knowledge available to them, and furthermore have no formalized way to access it. Knowledge management can make tacit knowledge accessible through an understanding of what tacit knowledge is available, e.g. through utilization of a database indicating people's expertise. It can also assist in codifying tacit knowledge to make it explicit, in order for it to be more readily available application in future innovations. Knowledge management can play a major role in facilitating collaboration, which can assist in the sharing of tacit knowledge.

The second major role that knowledge management plays in the innovation process is related to explicit knowledge. Although explicit knowledge does not play such a dominant role as tacit knowledge in the innovation process due to the fact that explicit knowledge about innovations is easily accessible to competitors, explicit knowledge is also an important component of innovation. In developed science processes, explicit knowledge features quite strongly in the research and development process with a rich exchange with tacit knowledge taking place. This process requires the capability to convert tacit and explicit product and process knowledge into explicit models. Whilst the knowledge from upstream research and development discoveries are usually tacit in nature, knowledge 
downstream in the value chain is largely explicit and codifiable in nature. It is important for organizations to build resources and capabilities that will allow them to capture and codify knowledge and product development routines, to ensure knowledge transfer can take place adequately (Cardinal et al., 2001; Scarbrough, 2003).

Rodan (2002) also argues that if one views the confluence of tacit and explicit knowledge elements that create a new idea as probabilistic, increasing the opportunities for the said confluence of knowledge elements should raise the frequency of new combinations occurring, thus positively impacting innovation.

Innovation is a process that recombines existing knowledge in new ways. Knowledge management can play a significant role in making explicit knowledge available for recombinations into new and innovative ideas. Knowledge management provides the tools, processes and platforms to ensure knowledge availability and accessibility, e.g. through structuring of the knowledge base. Knowledge management can also ensure that explicit knowledge, which can be used as input to the innovation process, is gathered internally and externally. Knowledge management finally also provides the means of ensuring the leverage of knowledge and to determine the gaps in the explicit knowledge base of an organization that could potentially negatively impact the organization's innovation program.

The third major role that knowledge management plays in innovation is through the enabling of collaboration. The author defines collaboration as the ability of customers, suppliers and employees to form knowledge sharing communities within and across organizational boundaries, that can work together to achieve a shared business objective, resulting in benefits to all community members.

Collaboration, both internal and external to the organization, plays an especially significant role in transfer of tacit knowledge and building collective know-how (Cavusgil et al., 2003; Pyka, 2002; Rodan, 2002; Scarbrough, 2003). The stronger the relationship between collaboration partners, the greater the extent of the tacit knowledge transfer (Cavusgil et al., 2003; Scarbrough, 2003). Gathering tacit knowledge from collaboration partners could potentially reduce risk and cost in innovation by ensuring a first-time-right approach, thus shortening development cycles and ensuring effective innovation (Cavusgil et al., 2003).

Pyka (2002) details ten types of collaborative relationships that have been identified as significant in the innovation environment. According to a number of authors the one that has received the most attention in literature and appears to be the most important is informal networks (Pyka, 2002; Rodan, 2002; Scarbrough, 2003). Formal relationships are increasingly displaced by informal relationships as mutual trust and confidence between partners are built up, thus creating efficient channels for knowledge flow. According to Pyka (2002) there is often a high incentive for innovators to seek needed information and knowledge 
from professional colleagues through informal networks as valuable knowledge is often available only in tacit format and collaboration is a quick and efficient way to access knowledge.

According to Cavusgil et al. (2003) and Scarbrough (2003), collaborative experiences positively affect the capability of firms to recognize and understand mechanisms for knowledge gathering, interpretation and diffusion (i.e. knowledge management practices), which increases efficiency of knowledge transfer.

Knowledge management can facilitate collaboration as mechanism to foster innovation through provision of technological platforms and tools to enable knowledge sharing within knowledge sharing communities, such as online discussion forums. It also fosters non-technical platforms or mechanisms for collaboration, such as competency groups. Knowledge management also provides the processes to ensure knowledge creation, sharing, gathering and leverage within these collaborative forums. Seeing that tacit knowledge is such an essential element in the innovation process, knowledge management plays a crucial role in ensuring the sharing of tacit knowledge in collaborative environments, but also codification of it into explicit format to enable re-use in different contexts.

The fourth major role that knowledge management plays in the innovation process is managing various activities in the knowledge management lifecycle, which consists of the phases of creation, gathering, sharing, leveraging of knowledge. Knowledge management plays a significant role in ensuring the integration of knowledge in the organization through provision of structure and organizational context, which enables knowledge sharing and leverage.

According to Chen et al. (2004) knowledge integration implies that timely insights can be made available to be drawn at the right juncture for sense making, i.e. knowledge can be exchanged, shared, evolved, refined and made available at the point of need. Without effective information and knowledge management to underpin knowledge integration, the organization is at risk in respect of inefficiently utilizing knowledge as resource for innovation. The potential benefits of knowledge cannot be realized without knowledge integration as the knowledge then rarely yields insight or deep representation (Baddi and Sharif, 2003):

There can be no full realization of the potential contribution of data intelligence to enterprise innovation without knowledge integration and no knowledge integration without full linkability and adaptability and thus dynamic representation of business information ... (Baddi and Sharif, 2003).

Knowledge management also plays a vital role in ensuring that knowledge required in the innovation process is available and accessible. Cavusgil et al. (2003) indicate that knowledge management can play a role in gathering tacit knowledge, internal and external to the organization, through application of 
processes to ensure availability of knowledge for innovation teams. This plays a significant role in driving down the risk and cost of innovation. Adams and Lamont (2003) indicate that organizations use knowledge management activities and tools, such as environmental scanning, benchmarking, intranets, firm-wide databases and communities to acquire knowledge and to make it accessible.

Adams and Lamont (2003) list several types of knowledge management lifecycle activities through which knowledge management systems can make direct contributions to the development of innovations that will ensure sustainable advantage. The first example is absorptive capacity, which refers to the organization's ability to recognize the value of new, external information, assimilate the information, and then apply the learned knowledge to its own product and service outputs. This is critical for development of new, innovative solutions and new core competencies within the organization. The second example is transformative capacity, which refers to the organization's ability to gather, assimilate, synthesize and redeploy knowledge to meet specific current needs. The knowledge management systems' functions of storage, retrieval and distribution are essential to transformative capacity development. The ability of the organization to develop its transformative capacity should grow as staff members are able to store vital knowledge on a knowledge management system and the system allows them to identify the existence and retrieval of stored knowledge. The knowledge management system should also facilitate communication and knowledge exchange across different organizational entities that share knowledge and experiences. The third example is provision, distribution and storage of internal knowledge needed to utilize organizational resources effectively. The fourth example is the creation, processing and distribution of knowledge to be assessed by organizational members for strategic decision-making. The final example is the examination of the external environment for identification of competitor activities and potential learning opportunities.

Knowledge management thus enables processes in the knowledge management lifecycle. It also manages the knowledge management lifecycle in the innovation process specifically and ensures integration of knowledge generated in the innovation process with the rest of the organizational knowledge base.

The fifth major role that knowledge management plays in the innovation environment is through the creation of a culture conducive for knowledge creation and sharing as well as collaboration:

Several researchers have emphasized the pivotal role of the management of knowledge, particularly in creating an internal working environment that supports creativity and fosters innovation (Gloet and Terziovski, 2004).

Gloet and Terziovski (2004) have also concluded that there is a significant and positive relationship between knowledge management practices and innovation 
performance, and that organizations therefore should strive for an integrated approach towards knowledge management, which assists in building a corporate culture, in order to maximize innovation performance leading to competitive advantage.

According to Scarbrough (2003) knowledge management's cultural contribution to innovation lie in its overlap with human resource management issues such as competence building. Knowledge creation, sharing and leverage build employee skills that are particularly relevant to the innovation process. Particular skills are required in specific innovation settings, and knowledge management can ensure that those individuals with the most appropriate skills sets are selected to assist in the innovation process. Knowledge management also contributes to creation of a culture conducive to innovation through the way that knowledge creation and sharing behavior is measured and rewarded:

The implications of these human resources management factors for the management of knowledge and innovation are profound. Where such factors are linked to the firm's business strategy, they may represent a powerful means of aligning employee skills and behavior with the flows of knowledge needed to develop innovations (Scarbrough, 2003).

In summary, knowledge management creates a culture within which the value of knowledge and application thereof is identified and communicated. Such a culture encourages knowledge based processes and programs, such as innovation. A knowledge sharing culture also creates behavioral change towards creation, sharing and leverage of knowledge, e.g. through performance measurement. Knowledge management creates a culture conducive to innovation and creativity.

\section{The value proposition of the role of knowledge management in innovation}

Knowledge management plays an invaluable role in innovation. The author defines the value proposition of knowledge management in the innovation process as follows:

- Knowledge management assists in creating tools, platforms and processes for tacit knowledge creation, sharing and leverage in the organization, which plays an important role in the innovation process. Knowledge management provides a focus in the organization on the value of tacit knowledge and assists in creating the environment for tacit knowledge creation, sharing and leverage to take place. An example would be through creation of communities of practice around areas of innovation that requires attention in the organization. Knowledge could also provide other platforms and processes for tacit knowledge sharing, such as breakfast briefings. Knowledge management can also facilitate 
tacit knowledge transfer across organizational and inter-organizational boundaries through ensuring that experts with relevant expert knowledge have opportunities to share their tacit knowledge through collaboration. Knowledge management can also assist in identifying stocks of available tacit knowledge.

- Knowledge management assists in converting tacit knowledge to explicit knowledge. It can provide both the platforms as well as the processes to ensure that tacit knowledge becomes explicit. Examples of codification platforms include discussion databases or online collaborative communities of practice. An example of a process to codify tacit knowledge to explicit knowledge is the capturing of tacit knowledge at tacit knowledge sharing events such as breakfast briefings into an electronic form where the knowledge can be organized and retrieved for later use. This adds a lot of value to the organization as it is known what knowledge is available, and it is retrievable for future re-use.

- Knowledge management facilitates collaboration in the innovation process. Knowledge management allows collaboration across functional boundaries within organizations, but also across organizational boundaries through online collaboration forums as well as organizational tools and platforms such as intranets and extranets. These collaboration forums are extremely valuable as they ensure the codification of knowledge utilized as input to the innovation process, but also generated as output of the innovation process. It provides accessibility to the knowledge and provides identification of collaborators in the knowledge sharing and innovation process, thus building up a reference of expertise and where it resides in the organization. It also ensures that knowledge external to the organization relevant to the organization's innovation processes is available and accessible.

- Knowledge management ensures the availability and accessibility of both tacit and explicit knowledge used in the innovation process using knowledge organization and retrieval skills and tools, such as taxonomies. It allows the organization and retrieval knowledge in a structured way according to the unique structures and value chain of the organization. It also provides search facilities and tools (e.g. Autonomy, Convera, and others) to enable staff to search for knowledge required in the innovation process. It provides a unique corporate structure to the corporate knowledge base. It can also make tacit knowledge more accessible through directories that identify individuals' areas of expertise in the organization.

- Knowledge management ensures the flow of knowledge used in the innovation process. Through the provision of collaboration forums and knowledge management processes, knowledge required for the innovation process can flow easily across functional boundaries as well as across organizational boundaries to facilitate internal and external collaboration. Creation of a knowledge sharing culture, which is an essential part of any 
knowledge management program, also stimulates knowledge flow, which is beneficial for innovation.

- Knowledge management provides platforms, tools and processes to ensure integration of an organization's knowledge base. Through knowledge management structures such as taxonomies, knowledge management can ensure the integration of the corporate knowledge base. This enables staff members to have an integrated view of what knowledge is available, where it can be accessed, and also what the gaps in the knowledge base are. This is extremely important in the innovation process to ensure that knowledge as resource is utilized to its maximum benefit and to ensure that knowledge is not recreated in the innovation process.

- Knowledge management assists in identifying gaps in the knowledge base and provides processes to fill the gaps in order to aid innovation. Through the structured provision of access to knowledge, knowledge management provides an overview of what is available in the organization. This allows the organization to understand in which areas knowledge is lacking and to systematically build the knowledge base in these areas. The organization may do this through the innovation program itself if the gaps are in strategic areas, but it may also do it through knowledge management processes or operational business processes.

- Knowledge management assists in building competencies required in the innovation process. Through knowledge accessibility and knowledge flow, staff members are able to increase their skills levels and knowledge both formally and informally. An increase in skills can improve the quality of innovation. The flow of knowledge across functional boundaries ensures that a wider base of knowledge is available to employees than only the knowledge they use in their day-to-day activities. Employees therefore have a wider frame of reference of the context in which they work and will therefore be able to innovate more efficiently. Knowledge management also provides a culture of knowledge sharing and accessibility of knowledge, creating an environment conducive to skills and competency building, which aids innovation.

- Knowledge management provides organizational context to the body of knowledge in the organization. Every organization's corporate memory is unique. The structures provided to organize and retrieve knowledge from the corporate knowledge base will therefore be providing a unique context to each particular organizational knowledge base. Provision of organizational context is critical in the innovation process, as innovation in the organization also takes place within a very specific business context. Knowledge management assists in identifying and understanding this organizational context.

- Knowledge management assists in steady growth of the knowledge base through gathering and capturing of explicit and tacit knowledge. It also assists specifically in addressing gaps in the knowledge base through specific acquisition of knowledge in those areas where gaps exist, or through knowledge creation and innovation itself. This in turn feeds the 
innovation process through creation of a much broader knowledge base that is available as resource for the innovation process. The tacit knowledge base also grows through building of skills due to the availability of knowledge.

- Knowledge management provides a knowledge-driven culture within which innovations can be incubated. Knowledge sharing is enhanced by a culture where the role of knowledge, knowledge management, innovation and creative thinking is encouraged. Most knowledge management programs have a strong knowledge culture element through which an organizational culture of knowledge generation and sharing is emphasized. This benefits innovation programs as it provides knowledge as resource, but it also provides a culture within which innovation, creativity and learning through mistakes are encouraged and valued.

\section{Conclusion}

Based on this article, it is clear that knowledge management plays a significant role in innovation. Further research is required, however, on the potential role of knowledge management in innovation and how the value of knowledge management can be maximized to ensure a more efficient and effective innovation process. Impact studies in this area may be extremely valuable, especially in organizations that have distinct knowledge management and innovation programs. It is important for both innovation and knowledge management professionals to understand the systemic relationship between these concepts and the value that it can generate in respect of creating and maintaining sustainable competitive advantage for organizations.

\section{References}

Adams, G.L., Lamont, B.T. (2003), "Knowledge management systems and developing sustainable competitive advantage", Journal of Knowledge Management, Vol. 7 No.2, pp.142-54.

Baddi, A., Sharif, A. (2003), "Information management and knowledge integration for enterprise innovation", Logistics Information Management, Vol. 16 No.2, pp.145-55.

Cardinal, L.B., Allessandri, T.M., Turner, S.F. (2001), "Knowledge codifiability, resources, and science based innovation", Journal of Knowledge Management, Vol. 5 No.2, pp.195-204.

Cavusgil, S.T., Calantone, R.J., Zhao, Y. (2003), "Tacit knowledge transfer and firm innovation capability", Journal of Business \& Industrial Marketing, Vol. 18 No.1, pp.6-21. 
Chen, J., Zhaohui, Z., Xie, H.Y. (2004), "Measuring intellectual capital", Journal of Intellectual Capital, Vol. 5 No.1, pp.195-212.

Darroch, J., McNaughton, R. (2002), "Examining the link between knowledge management practices and types of innovation", Journal of Intellectual Capital, Vol. 3 No.3, pp.210-22.

Du Plessis, M., Boon, J.A. (2004), "The role of knowledge management in eBusiness and customer relationship management: South African case study findings", International Journal of Information Management, Vol. 24 No.1, pp.7386.

Gloet, M., Terziovski, M. (2004), "Exploring the relationship between knowledge management practices and innovation performance", Journal of Manufacturing Technology Management, Vol. 15 No.5, pp.402-9.

Herkema, S. (2003), "A complex adaptive perspective on learning within innovation projects", The Learning Organization, Vol. 10 No.6, pp.340-6.

Parlby, D., Taylor, R. (2000), "The power of knowledge: a business guide to knowledge management", available at: www.kpmgconsulting.com/index.html, .

Pyka, A. (2002), "Innovation networks in economics: from the incentive-based to the knowledge based approaches", European Journal of Innovation Management, Vol. 5 No.3, pp.152-63.

Rodan, S. (2002), "Innovation and heterogeneous knowledge in managerial contact networks", Journal of Knowledge Management, Vol. 6 No.2, pp.152-63.

Scarbrough, H. (2003), "Knowledge management, HRM and the innovation process", International Journal of Manpower, Vol. 24 No.5, pp.501-16.

Shani, A.B., Sena, J.A., Olin, T. (2003), "Knowledge management and new product development: a study of two companies", European Journal of Innovation Management, Vol. 6 No.3, pp.137-49.

\section{About the author}

Marina du Plessis has extensive experience as a knowledge management and business strategy advisor to a variety of companies in numerous industries, including banking, insurance, telecommunications and manufacturing. She has worked in the field of knowledge management in Africa, the UK, Europe and the US. She holds a PhD in Information Science (University of Pretoria, South Africa - 2003), specializing in the role of knowledge management in eBusiness and customer relationship management. Marina du Plessis can be contacted at: marinaduplessis@discoverymail.co.za 